\title{
Los imperativos del exilio (A propósito del centenario de María Zambrano)
}

\author{
ANTOLÍN SÁNCHEZ CUERVO \\ Instituto de Filosofía del CSIC, Madrid
}

RESUMEN. Pocas trayectorias vitales e intelectuales han estado tan ligadas a la experiencia del exilio como la de María Zambrano (1904-2004). Lejos de agotarse en una mera circunstancia biográfica, fue esta experiencia el abono constante de toda una reflexión desde y sobre el margen, en respuesta a la crisis de la subjetividad occidental. La memoria, entendida como un rescate interpelador de sus rostros perdidos, velados bajo la violencia avasalladora de la historia europea, y a contrapelo siempre de toda comprensión lineal, objetiva o discursiva del pasado, desempeña un papel singularmente relevante dentro de esta reflexión. Es por ello que centenarios como el de María Zambrano invitan, no ya a rememorar una de las obras filosóficas más importantes del exilio español del 39, sino también a revisar el sentido de las efemérides. A descubrir, bajo la objetividad de las mismas, algo más que historia.

Si toda efeméride invita a revisar, no ya un determinado pasado, sino también las diversas miradas que se proyectan sobre él, mayormente to hace cuando señala ausencias, silencios u olvidos cuya actualidad decide sobre la tradición más reciente
ABSTRACT. Few vital and intellectual trajectories have been so bound to the experience of the exile like that of Maria Zambrano (1904-2004). Far from being drained in a simple biographical circumstance, it was this experience the constant nourishment of an entire reflection from and on the margin, in answer to the crisis of the western subjectivity. The memory, understood as an interpolating rescue of their lost faces, veiled under the overpowering violence of the European history, and against the grain always of all objective or discursive understanding of the past, plays a part singly inside this reflection. It is for it that centennials as that of María Zambrano invites, not already to remember one of the most important philosophical works in the Spanish exile of 1939, but also to revise the same sense of the anniversaries. To discover, under the objectivity of the same ones, something more than history.

y funda expectativas sobre el futuro más inminente. Tal es el caso de los exilios, y pocas trayectorias vitales e intelectuales han estado tan ligadas al exilio como la de María Zambrano (1904-2004). Ni mucho menos se agota la amplia y compleja sig- 
nificación del exilio zambraniano en una simple circunstancia biográfica, aun cuando encontrara en ella, en medio de geografías diversas y a lo largo de casi medio siglo, un abono constante. La experiencia biográfica del desarraigo condicionó sin duda el rumbo de no pocos itinerarios filosóficos de María Zambrano, pero al mismo tiempo desahogó toda una reflexión desde y sobre el margen, ya palpable en sus primeros escritos. Por ejemplo, en Horizonte de liberalismo (1930), en donde la pregunta por la raíces de la política obliga a prolongar la razón vital de Ortega hacia veredas que el maestro divisó sin llegar a transitar por ellas, más próximas a ciertos itinerarios schelerianos, hasta dar con la misma condición de posibilidad de todo pensamiento lógico o analítico: la intuición, en el más amplio sentido del término, como el recurso epistemológico de una razón integral o como una revelación no dogmática, semejante a una «avenida de lejana perspectiva» 1 , desde la que se van despejando las contradicciones del liberalismo racionalista. Este, bien es cierto, libera al hombre como individuo o como un sujeto de derecho, pero a costa de asolarlo, de confinarlo en el ámbito de una razón aséptica, disgregadora y pragmática que ha roto vínculos con su misma vitalidad radical - de orden tanto «suprahumano» como «infrahumano»: «la fe, el amor», «los apetitos, las pasiones» ${ }^{2}-, y$ termina por erigirse en agente de dominación social y económica, así como de legitimación de una humanidad escindida en élites y masas. Frente a lo cual se van asimismo despejando claves de un «nuevo liberalismo», arraigado en ese mismo sentir originario y total avasallado por la moral ilustrada, cuyo trasunto político es la democracia radical asumida en términos de una unidad elástica en la que caben todas las diferencias. $Y$ tal es el caso, también, de Hacia un saber sobre el alma (1934), entendida ésta, precisamente, como esa conexión vital de lo humano con lo divino y lo natural que el idealismo, pri- mero, redujo a un objeto metafísico, y el positivismo, después, a una noción de la psicología científica. Es decir, como hilo conductor de un «saber más amplio» que sea «Razón de toda la vida de hombre» y responda a esa «llamada a los poderes cósmicos que hace el hombre cuando le duelen las entrañas de la vida» ${ }^{3}$.

Asimismo, si el retorno a España de María Zambrano en 1984 supuso un acontecimiento en la cronología de su vida, quizá no lo fuera tanto en la evolución de la misma por dentro - en esos mismos términos intrahistóricos que pudo encontrar en sus lecturas de Unamuno-, pues biografía y pensamiento habían madurado ya, entrelazados, bajo el signo del desarraigo. Aún es más, sólo tras el regreso parece la experiencia del exilio irradiar su significación más plena. «Hay ciertos viajes» - afirmará en este sentido la propia Zambrano- «de los que sólo a la vuelta se comienza a saber», y es «desde esa mirada del regreso» que el exilio adquiere una significación «esencial», pues es «como una dimensión de una patria desconocida $[. .$.$] que una vez se conoce, es$ irrenunciable», suscitando su evocación «una sensación ininteligible, pero que es» ${ }^{4}$. O es también asimilación - sugerirá en otro lugar - de un «saber de experiencia» cuyo fruto se asemeja a «la pureza de los racimos de uvas» por su «tersura», su «transparencia» y su «perfección» ${ }^{5}$. Saber que en algo recuerda a esa síntesis de verdad y vida que la propia Zambrano había trazado en La confesión, género literario y método (1943), como respuesta a las carencias del género filosófico convencional, siempre oscilante entre la dispersión de la una en el relativismo de los hechos y-sobre todo- la humillación de la otra a manos de una razón ensoberbecida. Es entonces el exilio vocación y destino reconciliados, reunión de las vivencias opacas e incomunicables de una existencia a punto de ser engullida por la historia bajo la legibilidad de una libertad a punto de lograrse. 
Una singular lucidez propia del conocimiento consumado, una cierta visión de atardecer que en algo recuerda a la tópica imagen hegeliana del búho de Minerva, cuyo vuelo recoge las contradicciones de la lucha diuma transformándolas en espíritu, pareciera entreabrirse en la retrospectiva zambraniana del exilio. Pero sólo aparentemente, pues señala en realidad este exilio un saber «auroral» propio de la madrugada más que del atardecer, que sigue el rastro de lo aún no nacido o nacido sólo a medias, del constante renacer desde una finitud siempre irresuelta -rasgo fundamental del hombre mismo, según la antropología zambraniana-. En definitiva, de las entrañas no esclarecidas y de las esperanzas enredadas en las ruinas de la historia, frente al reduccionismo identificante inscrito en toda pretendida reconciliación entre razón y realidad. No en vano evocaba Zambrano el exilio en términos de una sensación «ininteligible, pero que es», o - añade en el mismo texto- «como de quien ha sido despellejado, como San Bartolomé»: apunta la filósofa hacia un saber del despellejamiento, por así decirlo, que comprenda y asimile toda aquella realidad ilegible bajo la mirada reductora y excluyente del sujeto occidental. Fruto de una salida precipitada del mundo trágico, se ve la razón filosófica abocada, desde sus mismos orígenes -desde sus primeras expresiones sistemáticas al menos, y salvando siempre ciertas intuiciones presocráticas ${ }^{6}$-, a una ambigüedad radical, pues lleva dentro de sí indicios de esa misma violencia arcaica de la que está llamada a librarse, preservándola y reproduciéndola una y otra vez de manera velada. Supone así claridad y ceguera, despliegue de toda una mirada que, sin embargo, ha dejado de ver las cosas. Ordena y legisla la realidad, pero a costa de sojuzgarla mediante la pregunta por el ser, de reducirla a un núcleo esencial y unitario que ahoga la experiencia vital. Media con la naturaleza a través de una elucidación de lo divino abocada a la disolución secular, dejando así al descubierto los abismos de lo sagrado en su expresión más bruta. Proyecta la existencia humana en una historia de libertad sometida, al mismo tiempo, a una inercia sacrificial imparable. Tal es, para Zambrano, el signo bajo el que ha transcurrido el humanismo occidental desde Platón hasta Nietzsche, cuyo nihilismo desenmascarador anuncia la recaída en lo más hermético y opaco de la realidad y con ello, no ya la crisis, sino el mismo suicidio de Occidente.

Toda la obra de Zambrano es una respuesta a esta «noche obscura de lo humano» - dirá en La agonía de Europa $(1945)^{7}$-, más allá de toda resignación cínica o posmoderna. Aquella vocación de descentramiento incipiente en los escritos de juventud encontrará, al unísono con el largo exilio que se inicia en 1939 , ricos cauces para su desarrollo. Desde «San Juan de la Cruz: de la noche oscura a la más clara mística» (1939) hasta «Notas de un método» (1988), pasando por El hombre y lo divino (1955) y Persona y democracia (1956) - obras gemelas, y radiantes dentro de la trayectoria zambranianase irá perfilando toda una crítica de la razón occidental y un abismamiento consecuente en sus márgenes, en busca de su alma y su rostro, sus ínferos y sus sombras; de esas mismas «formas íntimas de la vida» o categorías zambranianas del ser - el tiempo, el amor, el rencor, la piedad, la nada, la muerte, la carne, los bienaventurados $^{8}$-, largamente anegadas bajo la noción falsificadora de experiencia que ha imperado en Occidente.

No se limita, por tanto, Zambrano a perfilar una mera reforma de la razón, sino que apunta más bien hacia todo un saber de salvación capaz de condescender ante las penumbras de la realidad, de rescatar aquello que el sujeto occidental abandonó a las puertas de la caverna en su prematura salida de la misma y de atemperar, en fin, 
la claridad cegadora del racionalismo. Lo cual requiere la articulación de una razón no dialéctica, ni representativa ni discursiva, ni siquiera narrativa, pues ninguna de ellas despeja cauces suficientes para una reconciliación, no de la razón consigo misma, sino con lo otro de sí, con aquellas experiencias vitales originarias de las que un día brotó para luego avasallarlas. Tiende por ello Zambrano un constante ir y venir entre la filosofía, la poesía y la religión, a lo largo del cual se va despejando una razón abiertamente heterodoxa, siempre en el límite entre la «otra ilustración» y el llamado, en su día, por Hans Jonas «síndrome gnóstico» 9 .

Una cierta tensión entre memoria e historia, en tanto que miradas más o menos antagónicas del pasado, podría en cualquier caso distinguirse en medio de estos itinerarios, como un hilo conductor de la condescendencia zambraniana y lo que a partir de ella se transluce. Como se podrá adivinar, señala esta memoria aquellos tiempos sumergidos y latentes propios de las formas íntimas de la vida - tanto individual como colectiva-, cuyo núcleo originario no es otro que la esperanza, y a contrapelo, siempre, de toda comprensión objetiva, lineal o discursiva de la temporalidad; del tiempo conciencialista de la fenomenología -salvo excepciones como la durée bergsoniana-; del historicismo -así el del propio Ortega, del que Zambrano comienza a desmarcarse en sus primeros escritos-; o de las teorías del progreso, que Hegel, Marx y Comte han formulado de manera paradigmática. A contrapelo, en definitiva, de la filosofía de la historia como tal, en tanto que saber canónico de la modernidad, pues lejos de rastrear las raíces íntimas de la temporalidad, ha permanecido fijada a su dimensión exclusivamente racional. De ahí su condición netamente reductora, pues tiende a agotarse en una justificación más o menos elaborada de la fatalidad en la que se halla inmerso el sujeto occidental, víctima de su propia «fe humanista»: en respuesta al destino ciego y opaco inscrito en todo orden mítico, éste ha proyectado su ser en la historia bajo un afán de orden, dominio y claridad que olvida aquellas dimensiones del tiempo ajenas a la voluntad racionalista. La historia, como realidad y como saber, discurre así bajo la coacción del tiempo unívoco y opresivo de la razón. Recoge falsamente los tiempos subjetivos e irreductibles de la esperanza bajo una pretensión racionalizadora y un afán objetivador abocado a la cerrazón, al absolutismo. He ahí el germen del utopismo moderno, el cual no hará sino recoger la abolición secular de lo divino para reabsorberlo en la historia humana bajo la pretensión de realizar en ella el trasmundo cristiano de la «Ciudad de Dios». Es por ello que la historia de Europa transcurre bajo el signo del endiosamiento y la deificación, de una especie de enajenación enmascaradora de lo divino que encuentra su mayor apogeo en las teorías ilustradas del progreso y muestra signos de consumación en la nietzscheana voluntad de poder. Tiene esta historia una constitución idolátrica que exige la producción incesante de víctimas en prenda por el cumplimiento de su esperanza exasperada. Es, en definitiva - argumentará Zambrano a lo largo de Persona y democracia-, una historia sacrificial, en la que no hay «palacio renacentista, ni castillo medieval, que no tenga prisiones bajo sus salones» ${ }^{10}$.

La memoria zambraniana despeja entonces los cauces de una suerte de filosofía negativa de la historia en la que se trasluzcan los motivos de su condición sacrificial y se alumbren las condiciones de posibilidad de su desencantamiento. Los cauces, en definitiva, de «un conocimiento purificador de las entrañas que engendran la historia», de «sus acciones más íntimas» y sus «ensueños escondidos». En línea con su perspectiva «auroral», persigue Zambrano una historicidad capaz de albergar el carácter radicalmente 
incipiente del hombre en tanto que ser condenado a padecer la trascendencia de su incesante despertar, en el límite, siempre, entre el sueño y la vigilia, entre la oscuridad de sus entrañas y la claridad de su libertad. Pasión fecunda en la medida en que pueda liberar aquellos tiempos latentes e irreductibles que conforman el núcleo mismo de la esperanza, proyectándolos en una existencia no opresiva, en una historia cuyo protagonista no sea «este pobre niño atormentado, ni ese pobre hombre, ni ese fantasma agobiado, ni ese monstruo, sino simplemente el hombre mismo, sin máscaras y con una carga apropiada a sus fuerzas» ${ }^{11}$.

Son abundantes y diversos los momentos de la obra zambraniana en los que aflora este sentido «purificador» de la memoria, en busca, siempre, del rostro perdido. El exilio, y su denso simbolismo, aglutina algunos de ellos. El exiliado - dirá Zambrano en la "Carta sobre el exilio» (1961) - es «el que, a fuerza de penas y trabajos, de renuncia, parece haberse salido de la historia y está en su orilla», reducido «a [...] lo irreductible: a la verdad de su ser, de su ser-así, despojado de todo». Figura del despellejamiento, «está más cerca de ser criatura de la verdad que personaje de la historia». Se ha despojado de sus razones y justificaciones, de sus ídolos y sus máscaras para quedarse «desnudo y desencarnado» ${ }^{12}$ a la intemperie del desierto, bajo una ausencia radical de toda mediación con el mundo: la casa, la patria y hasta el propio firmamento, más allá del amparo que le brinda toda «tentación de existir». Tentación - dirá Zambrano en alguna de sus reflexiones más maduras sobre el exilio, recogidas en Los bienaventurados (1990) - «de ser el existente en medio de esa soledad dejada por el desamparo y aun por el abandono» ${ }^{13}$, pues es la existencia reducto de la subjetividad moderna aun cuando se ha desprendido de su sustancia idealista para reducirse a un puro estado de arrojo, al preservar, como tal, su vocación de certidumbre. Precisamente la tentación de existir es uno de los motivos que bien podrían centrar la ambigua sintonía de Zambrano con Heidegger. La vocación de exilio invita sin duda a transitar por ciertas sendas perdidas, pero también a retirarse de ellas cuando ofrecen demasiadas señales: el «Dasein» está tocado por la llama del ser, es su interlocutor y está traspasado por la luz de su pregunta, es mediación con el mundo desplegada en el tupido análisis de su condición existencial. Por eso dicha vocación no se colma tanto en un estar en el mundo como en un estar fuera de él -en un afuera que también es adentro, ínfero-, en ese lugar sin mediación ninguna, siquiera el firmamento, que es «desierto sin fronteras» pero también «sin espejismos» ${ }^{14}$, y cuyo vaciamiento se desliza entre las categorías de la fenomenología existencial, reconociéndose mayormente en la transparencia de la mística.

Pero afronta también el exiliado la tentación de salvar las circunstancias, de renunciar a su exilio por mor de ellas. Un cierto adiós a Heidegger, y también a Ortega, se va despejando en la fenomenología zambraniana del exilio. En realidad, las diferentes posturas que maestro y discípula sostuvieron durante y después de la guerra no hicieron sino desahogar y acentuar las divergencias - tanto políticas como filosóficas - que ya se habían ido destilando a lo largo de la década anterior. Latían, en el fondo, dos concepciones reñidas de la crisis, tanto de España como de Europa y, en definitiva, de Occidente: ese temple en definitiva «ilustrado» que persiste bajo la razón histórica cuando ésta apuesta por la continuidad de la historia y por el papel reformador que las élites intelectuales están llamadas a desempeñar en ella, y que teóricamente justificaría el regreso de Ortega a España en 1945, no podía menos que colisionar con el talante trágico de su discípula. Tan proclive, ella, al abismamiento en los márgenes de esa misma his- 
toria, a duras penas podrían sus exilios medirse en las categorías orteguianas. Para Zambrano, el paso por las armas de la legitimidad republicana y la subsiguiente dictadura, o el no intervencionismo de intelectuales de adentro y gobernantes de afuera, no sólo son circunstancias insoportables que hacen inevitable el exilio e imposibilitan el regreso; son, además, precisamente eso y «nada más» que eso: «circunstancias», o lo que es igual en términos zambranianos, máscaras, superficies de la historia deificada de Occidente cuya violencia, largamente incubada en el meollo de la subjetividad moderna, insta igualmente al exilio, a la salvación en el margen. Exilio es entonces algo más que una circunstancia. $\mathrm{O}$ es, cuando menos, confín de la misma y trascendencia de su límite. $\mathrm{Y}$ en todo caso, desmarque de su restricción filosófica: si Ortega eludió el exilio apelando a las circunstancias, María Zambrano lo abrazó apelando a la realidad que se vela tras ellas. El modo pleno de verlas - dirá en este sentido en Los bienaventurados- «sería el verlas del otro lado, el darlas la vuelta invirtiendo así la situación entre ellas y el sujeto, que en vez de estar por ellas cercado las rodearía él». Mediante este «movimiento de circunambulación», el sujeto vencería la resistencia que levanta su propia afirmación en términos de «Razón Vital», es decir, «como el punto de partida dado radicalmente en la realidad que es su vida», pues antes de afirmarse como tal, «trata con la realidad sintiéndola y sintiéndose despojarse de su afirmación [...]». Las circunstancias dejan entonces de mostrarse como un cerco, pues desde más allá de ellas «se llama al que busca el conocimiento, que es simplemente el que no abandona, el que no suspende el sentir originario, el que no desoye ni desatiende la presencia no objetiva de algo, de un centro que a sí mismo y a su contorno trasciende» ${ }^{15}$.

Ese centro descentrador es el imán de todo exilio, entraña misma de la historia en la que el exiliado se adentra una y otra vez para rescatar «lo rescatable, lo irrenunciable» 16: el sueño sumergido, fracasado o «mal soñado» de toda una época, toda una tradición y hasta de la historia misma, condensado en un instante de suspensión, en un «pasado que se ha quedado quieto» y «que es pura presencia» ${ }^{17}$. En un tiempo, por así decirlo, desubicado, «utópico» en un sentido nada moderno ni convencional, aunque sí muy literal del término. No como oclusión racionalista de la historia, resultante de una proyección exasperada de la esperanza, sino de más bien todo lo contrario, como transparencia de lo que no tiene tópos: «la ciudad no habitada, la historia que desde el principio quedó borrada», que el exiliado «vislumbra» ${ }^{18} \mathrm{y}$, sobre todo, trasluce, pues es, antes que cualquier otra cosa, una figura de la mediación. Su ser consiste así en transparentar. Es por sí mismo «una especie de revelación». Sin casa ni patria, anda «librado a la visión proponiendo el ver para verse». Es presencia escandalosa, objeto de visión antes que sujeto de la misma. $O$ es el sujeto de un tiempo que, por su condición desnuda e irreductible, es «dios sin máscara» y, más aún, «Dios de la visión» ${ }^{19}$. Entre el ver y el ser visto, deja el exiliado al descubierto esa historia siempre borrada que es la utopía de una «historia ética», misma que asoma en la tercera y última parte de Persona y democracia. Ha arrancado un poco de verdad a los ínferos de la pólis y es por ello - dirá Zambrano a propósito de Antígona- «revelación de «la Nueva Ley» ${ }^{20}$, «vida y visión en el speculum justitiae» ${ }^{21}$. Su ser, en realidad, no consiste sólo en transparentar, sino también en donar. Si se ha quedado al borde de la historia, «en un indecible olvido», no ha sido «para que lo salven a él [...], sino para que quien lo recoja en el momento en que deba ser, reciba algo que sólo él tiene»: una "palabra diáfana» como «prenda que un día dará, que se desprenderá de él sin violencia, de la misma 
manera que él se ha desprendido de todos sus ropajes y figuras, incluso de las más legítimas» ${ }^{22}$. Toda una ética de la desnudez y la desolación se va tejiendo en torno a la experiencia zambraniana del exilio.

Es en estos mismos términos cómo Zambrano reivindicó la transparencia del propio exilio. En la ya citada «Carta sobre el exilio» hizo suya la piedad de Antígona. Escrita en 1961, cuando las expectativas de una pronta caída del régimen se han quedado ya muy atrás y el exilio es pasto del olvido, está dirigida no tanto a los enemigos de siempre como a las nuevas generaciones antifranquistas. A los «anticonformistas de hoy», quienes consideran «que la suerte y el destino de España deben estar y estarán determinados sólo por la acción y aun por el pensamiento de ellos, los que están en España», y piden, por tanto, al exiliado que renuncie a su exilio «hasta el punto de casi ignorarlo, olvidarlo y desconocerlo», pues para ellos «el exiliado ha dejado de existir ya, vuelva o no vuelva» ${ }^{23}$. Temen que el pasado que encarnan convoque al fantasma de la guerra civil y quieren, por ello, que sea eliminado del horizonte actual y se confunda con el presente. Presos de su propia visión sacrificial de la historia, piensan que el fin de la dictadura sólo puede lograrse en términos de progreso o de continuidad. Es decir, al margen de un pasado que, por muy doliente que fuera, no cabe en un presente que sólo debe mirar hacia el porvenir, guiado por las élites que han encontrado acomodo en él. Sin embargo - dirá Zambrano entreabriendo una mira- da anamnética que en algo recuerda las tesis sobre la historia de Benjamín-, es en el olvido y no en la memoria donde anida el fantasma de la violencia, pues el exiliado se ha llevado consigo un pasado que pide ser reconocido en su verdad, no para realizar anacrónicamente aquello que pudo ser y no fue - en este caso, aquella singular plenitud enarbolada por la generación de 1930, cuyas expectativas republicanas se vieron ahogadas en la guerra civil—, sino más bien para liberar al presente de su indigencia. Para traspasar, precisamente, ese umbral trágico de la guerra bajo el que permanecen detenidos tanto los partidarios del régimen como sus críticos de adentro, y bajo el que la misma historia de España permanece hechizada desde hace siglos. Es ésta la prenda - afirma Zambrano hacia el final de la carta- «que el exiliado conserva entre sus manos, mientras mira el cielo sin interrogación y sin llanto». Désele, por ello - prosigue-, «Voz y palabra», pues «no pide otra cosa sino que le dejen dar, dar lo que nunca perdió y lo que ha ido ganando: la libertad que se llevó consigo y la verdad que ha ido ganando en esta especie de vida póstuma que se le ha dejado» ${ }^{24}$.

Centenarios como el de María Zambrano no sólo invitan, en fin, a rememorar una trayectoria vital e intelectual ampliamente significada, sino también a darle un sentido a las efemérides. A descubrir, bajo la objetividad de las mismas, el desahogo de tiempos utópicos, el comienzo de una historia siempre borrada, la fidelidad a una vida póstuma.

\footnotetext{
${ }^{\prime}$ Horizonte de liberalismo, edición y estudio introductorio a cargo de Jesús Moreno Sanz, Madrid, Morata, 1996, p. 227.

2 Ibid., p. 244

${ }^{3}$ Hacia un saber sobre el alma, Madrid, Alianza, 2000 , pp. 29 ss.
}

${ }^{4} A B C, 28$ de agosto de 1989, p. 3. Cf. también $L a$ otra cara del exilio: la diáspora del 39, El Escorial, Universidad Complutense, curso de verano de 1989 , pp. 7 s.; María Zambrano, Las palabras del regreso (artículos periodísticos, 1985-1990), ed. de Mercedes Gómez Blesa, Salamanca, Amarú, 1995, pp. 13 s. 
5 «El saber de experiencia (notas inconexas)», Diario 16, núm. 23 (sup. «Culturas»), Madrid, 15 de septiembre de 1985, p. III; María Zambrano, Las palabras del regreso, pp. $15 \mathrm{ss.}$

6 Como la que recoge Empédocles bajo la máxima «repartir el lógos por las entrañas», muy recurrida por Zambrano en diversos lugares de su obra.

7 María Zambrano, La agonía de Europa, ed. de Jesús Moreno Sanz, Madrid, Trotta, 2000, p.

${ }^{8}$ Zambrano formula y expone estas fromas en varios lugares de su obra. Cf. los textos reunidos en el apartado VIII de la antología crítica María Zambrano, La razón en la sombra, ed. de Jesús Moreno Sanz, Madrid, Siruela, 2004, pp. 615-671.

9 Sobre esta cuestión, en el contexto de una amplia y completa panorámica de los itinerarios zambranianos, cf. la Introducción de Jesús Moreno Sanz a la antología de textos citada en la nota anterior.
${ }^{10}$ Persona y democracia, Madrid, Siruela, 1996, pp. $56 \mathrm{~s}$.

1 Ibid., p. 88.

12 Cf. Cuadernos del Congreso por la Libertad de la Cultura, núm. 49, París, pp. $66 \mathrm{~s}$.

${ }^{13}$ Los bienaventurados, Madrid, Siruela, 1990, p. 39 .

14 Ibid., p. 36.

I5 Ibid., pp. $60 \mathrm{~s}$

16 «Carta sobre el exilio», p. 69.

17 Ibid., p. 67.

18 Los bienaventurados, p. 35.

19 Ibid., pp. 32 ss.

20 Senderos, Barcelona, Anthropos, 1986, p. 204.

21 Ibid.s p. 213.

22 «Carta sobre el exilio», p. 67.

23 lbid., p. 68

${ }^{24}$ Ibid., p. 70 